\title{
ROMANSKE SLEDI V TOPONOMASTIKI VOJVODINE
}

Ko govorimo o romanski prisotnosti v toponomastiki Vojvodine, se moramo zavedati naslednjih dejavnikov: Vojvodina ni avtohtono romansko ozemlje; če zanemarimo cerkveno latinščino, so romanske prvine prisotne le po zaslugi italofrancosko-španskih kolonistov ali sosednjega romunskega naroda. V zvezi z romunščino se vprašanja kar kopičijo: ali je romunsko Slatina ali Jeselnica sploh romansko? Po profesorju Skoku je romansko le Valişora. ${ }^{1} \mathrm{~V}$ temle delcu se bomo torej ukvarjali s prvim virom za krajevna imena. Ko gre za latinščino, ponuja profesor Skok (v navedenem delu) nekaj primerov: Monoštor $(<$ monasterium), Banoštor ( $<$ monasterium Bani, Bani monasterium), Apatin ( $<$ Abbati (falva)). Tudi za reko Tiso naj bi bila vir latinščina (Pathissus), kjer se lepo vidi vpliv slovanskega afereznega dejavnika.

$\mathrm{Na}$ poti $\mathrm{k}$ romanskim toponimom se nam zdi eden najstarejših (iz leta 1370) Manđelos na Fruški gori, čeprav ni neposredno romanski. Milanski duhovniki, ki so v srednjem veku pribežali tja, so si postavili naselje, ki so ga sosednji Madžari imenovali (falu de) Nagy-Olasz (vélika italijanska vas), kar so Srbi po svoje spremenili v Manđelos. $^{2}$

Začenjajo se živahnejše zveze in do obogatitve vojvodinske toponomastike $\mathrm{z}$ romanskimi prvinami prihaja v 18. stoletju, ko se to ozemlje kolonizira. Po odhodu Turkov v začetku tega stoletja je namreč avstrijska monarhija začela naseljevati Nemce, Madžare, Slovake in druge narode, ker je želela zapolniti praznine ( $v$ prostoru in prebivalstvu) in ustvariti nekak obrambni zid proti Turkom. Vodilna ideja je bila tudi sprememba demografske podobe južnih provinc. Nemci do prihajali iz zahodnih predelov Nemčije, saj si Dunaj ni hotel zmanjšati davčnih prihodkov. Po drugi strani pa so velika revščina, poplave in lakota v zahodni Evropi le večale splošno navdušenje za odhod in naselitev na plodnih tleh Banata in Bačke. Mimogrede, Dunaj je širil nezaslišano propagando $\mathrm{z}$ lepaki, opozorili in oglasi $\mathrm{v}$ tisku. Zelo dejavno vlogo so imeli Werbekomissäre in Winkelagenten, osrednjo vlogo pa je igrala vojska. „Um die Werbung zu einem vollen Erfolge zu führen und intensiver zu gestalten, wurden die österreichischen militärischen Rekrutenwerbeposten im Reiche ermächtigt, für die Auswanderung nach Ungarn zu werben. "3 In tako so prišli v Banat in Bačko tudi Francozi iz Alzacije in Lotaringije. V tem obdobju je prišlo v treh kolonizacijskih valovih (prvi je bil v letih 1718-1736, drugi v letih 1745-1771, tret-

1 Toponomastika Vojvodine, v: Vojvodina I, 1939, str. 122. Zadnji kraj danes ni v Jugoslaviji.

2 Prav tam, str. 118.

3 Stanglica, Die Auswanderung der Lothringer..., str. 30. 
ji pa v letih 1782-1787) okrog 30 tisoč francosko govorečih ljudi. ${ }^{4}$ Zbirno mesto je bil Mercydorf (danes Merțişoara - vas, ki od leta 1918 pripada Romuniji), v tem času pravo zbirališče Romanov, saj so tja prihajali tudi Italijani in Španci. Potem ko so jim oblasti zagotovile hiše in drugo za življenje in delo, so jih porazdelile po vsem ozemlju Banata. To pomeni, da so kolonisti ponekod prihajali v že obstoječe vasi, iz katerih so bili na silo odseljeni Srbi in Romuni, drugje pa so si morali sami zgraditi hiše in si tako organizirati vasi in skupno življenje (npr. vasi Charleville, Saint-Hubert ali La Nueva Barcelona).

Španci so imeli različne poti in usode. Po avstrijski izgubi Neaplja in Sicilije so številne španske družine prišle na Dunaj, saj so sledile habsburški vojski in državnemu aparatu. Tuje ozračje, drugačna miselnost in nasploh drugačne razmere so prispevali k temu, da se Španci tam niso dobro znašli. Ker številnim incidentom ni bilo videti konca, jih je dunajska vlada „ekspedirala“ vzdolž Donave v Banat. Po prihodu so jih kolonizacijske oblasti razpršile po mestih in vaseh $-\mathrm{z}$ eno izjemo: La Nueva Barcelona (ki je danes predmestje Zrenjanina) je bila „etnično čista“. K zginevanju te etnične skupine je prispevalo po eni strani podnebje (močvirje, malarija), po drugi pa izbruh turške vojne leta 1736 , ki jih je pognala na sever proti Budimu. Nekatere družine so ostale, predvsem v drugih vaseh, o čemer danes pričajo priimki španskega izvora v Vojvodini: Juanin, Gerun, Kasteljanov.

Usoda je bila Italijanom veliko bolj naklonjena. Dunajska vlada je želela v državi razširiti in obogatiti kulturo oljke in riža ter svilogojstvo in obrtništvo, zato je kolonizirala Banat s številnimi družinami iz Benečije, Furlanije in Lombardije. Po prihodu v Banat in po razdelitvi je bila največja koncentracija Italijanov v Temišvaru, vendar so bile tu in tam tudi banatske vasi dopolnjene $\mathrm{z}$ italijanskimi družinami.

Vse tri romansko govoreče skupine so se zelo hitro asimilirale. Že po drugi generaciji so le redki v vsakdanjem življenju govorili francosko, italijansko ali kastiljsko/katalonsko, razen $\mathrm{v}$ kakih družinskih pogovorih ali pri molitvi. Zadeve postanejo bolj jasne, če upoštevamo, da je bil uradni jezik do leta 1867 nemščina (pri notarjih in nasploh v pisni rabi tudi latinščna), potem madžarščina in od leta 1918 dalje srbohrvaščna. Le tu in tam kak priimek priča o romanskem izvoru teh prebivalcev.

V naslednjem seznamu so navedena nekatera krajevna imena, ki so zanimiva $z$ vidika romanistike ali ki s svojo podobo kažejo na prisotnost treh tu obravnavanih etničnih skupin. Imena so, kjer je le mogoče, prikazana v treh fazah - nemški do leta 1867 , madžarski do leta 1918 in sodobni po letu 1918 (ponekod po letu 1945).

Kratice: $m j r .=$ majur, $p s z, p s t=$ pusta(ra), $t n=$ pristava, posestvo.

4 Arsenijević, La présence des Français... 
ABAVIJA - Abbaziapsz 1881, Abbaciapsz 1916, Abazija (pustara 1925, naselje od 1935, Abavija 1946), severovzhodno od Vršca.

BANATSKO VELIKO SELO - gl. Charleville, Saint-Hubert in Seultour.

BARANDA - južni Banat, zahodno od Kovačice, 1853, po tem letu isto; < it. baraonda 'zmeda, nered, direndaj'.

BOZITO - severovzhodni Banat, Bozito psz 1894; < fr. beau-site.

GILLE PSZ - osrednji Banat, jugovzhodno od Zrenjanina, 1881. Danes ga ni več.

ILANDŽA - osrednji Banat, severovzhodno od Alibunarja; Illancsa 1853, Ilanža 1858, Illanzsa 1854, Illandzsa 1878 - danes Ilandža. Glasovna podoba in ortografija kažeta na romanski vir. Čeprav pisava ni nikoli dokaz, pa niti v nemški niti v madžarski pisavi ne srečamo dvojne črke $l$ drugače kot v tujkah. Beseda je najbrž aferezno okrnjena: $v>\varnothing, v$ izglasju pa je zamenjava $/ 3 />/ \mathrm{d} z / . \mathrm{Iz}-$ virnik naj bi bil jukstaponirani zloženi samostalnik. ${ }^{5}$

LAUDANOVAC - jugovzhodni Banat, ob železniški progi Vršac-Zrenjanin. Laudon Tanya 1912, Loudon tn. 1916, Laudanovac 1925.

MASIMOVA PST - južni Banat, vzhodno od Debeljače, 1854. Zanimivo je, da je že pri prvi pisni omembi tega ledinskega imena obstajala italijanska oblika, in to kljub uradni nemščini in okoliški srbščini.

MEĐA - osrednji Banat, severovzhodno od Zrenjanina, na vzhodni državni meji. Pardány 1853, Pardany 1854, Bardány 1864, Szerb-Pardany in NémetPardany... Međa od leta 1947. Krajevno ime najbrž izvira iz romanskega, tj. it . in šp. bardana, fr. bardane (toda romunsko ciulin) $>$ Bardan $>$ Pardanj, v pomenu 'navadni repinec, čičak', kar ni presenetljivo, saj so pogosti srbski toponimi Čičovac, Čičatovac. Na tem ozemlju vsaj te rastline ne primanjkuje. Tudi položaj naglasa kaže na romanski izvor.

MIĆUNOVO - severna Bačka, severovzhodno od Bačke Topole. Karkatur. Šele od leta 1918. Razen med prebivalstvom ime kraja v pisni obliki do tega leta ni potrjeno. Zanimivo je, da je leta 1946 zapisano kot „kolonija Karaktur“. Od leta 1947 dalje Mićunovo. Verjetno narečno v pomenu 'jarek', 'rov' - prim šp. curcava, carcavina, carcavo, carcavon, stšp. cargadura, it. caricatura $<$ caricare. Sicer ob fr. carcan in carcasse etimološki slovarji pravijo „origine incertaine“. Zdi se mi, da je v vseh primerih pomen 'luknja', 'zasek', 'zareza'. Morda 'pokopališče'?

NUEVA BARCELONA (La) - danes Zrenjanin, do leta 1918 Gross/Nágy/ Veliki Bečkerek. Takšno je bilo ime dela Zrenjanina v letih 1736-1739. Deželna administracija je hotela skoncentrirati S̆pance, razkropljene po vsem Banatu, zato je izbrala kraj pri Zrenjaninu in tam naročila izgradnjo hiš za koloniste. Ti so v začetku leta 1736 res prišli in začeli novo življenje. Po podatkih, ki jih imamo danes, Španci niso mogli prenesti neugodnega podnebja, k njihovemu odhodu pa je prispevala tudi turška vojna v letih 1736-1737, tako da se je ta španska „epizoda“ v Bečkereku končala $\mathrm{z}$ množično selitvijo na sever, do Budima, kar je trajalo vse do leta 1738 . V te hiše so oblasti naselile pred Turki

5 Na tem mestu me prof. Nezirović opozarja na morebitni turški vir iliď̆ (kot llidža pri Sarajevu) v pomenu 'toplice' $(<$ tur. il/c $a)$. 
bežeče Nemce iz Beograda. Zanimivo je, da so bili preostali Španci po banatskih vaseh bolj iznajdljivi in da načelno niso zapustili svojih tal. Ime La Nueva Barcelona se je držalo med srbskim in nemškim prebivalstvom vse do začetka 20. stoletja, ko nekdanja okoliška vasica postane predmestje Bečkereka Zrenjanina in potem dobi novo ime - Mala Amerika.

ODESCALCHI PST 1890, osrednji Srem, jugozahodno od Manđelosa, in

ODESCHALCHI PST 1881, zahodni Srem, zahodno od Čalme. Oba toponima izvirata iz imena znane aristokratske družine, ki je imela v Sremu velika posestva, kar 35 naselij, od katerih je bilo 19 zgornjesremskih in 16 spodnjesremskih.

ORZOVA PST - osrednji jugovzhodni Banat. Orsopsz 1881, Orzova pst 1932. Italijanski samostalnik orso pomeni 'medved', je pa tudi italijansko lastno ime, celo rodbinsko.

PLANDIŠTE - osrednji jugovzhodni Banat, severovzhodno od Vršca. Zichyház 1851, Zichydorf 1853, Morminta, Mormintyé, Zichyfalva 1878, Zičiselo 1920 -1923, Mariolana 1922 in do 1947. Danes Plandište. Ime mesteca se je večkrat menjavalo, začenši pri grofu Zichy-Ferrarisu, čigar last je bilo, do današnje oblike Plandište. Zelo zanimivo je obdobje imena Mormintyé, ki ga srečamo še v 18. stoletju, natančneje od leta 1726 , ko so tja prišli prvi francoski kolonisti (ob nemških), v okviru tako imenovane karolinške kolonizacije (1718-1737). Iz tega obdobja so v Vršcu in okolici družne Boisse, kar je pozneje prešlo v Boas in celo v Božić; Maçon > Maßjung, Massiong, Massio, Mason; Duchamp > Duchon, Douchon, Dušan (kot priimek); Lorette $>$ Loreth; Pitance $>$ Bittansch, pozneje Bićanić. ${ }^{6}$

SOLTUR - pri Kikindi, na državni meji z Romunijo. Seultour 1771 , ko je bila ustanovljena vas oziroma ko so $\mathrm{v}$ posebej zanje zgrajeno vas prišli prvi francoski kolonisti. Nekdanja naselja na tem kraju so bila uničena med turško vojno leta 1550. Na praznem prostoru se je ohranil le en na pol porušen stolp. Francozi so si za vas izbrali ime po tem stolpu, saj je to bil „la Seule Tour“, ki ga je bilo na ravnem zlahka videti. Zanimivo je, da so za zaščitnico vasi izbrali sveto Barbaro, zaščitnico istoimenske lotarinške vasi, ki je prav tako znana po stolpu. Tu naseljeni kolonisti so prišli iz okolice francoskih mest in vasi - Metz, Arracourt, Francheville, Moyenvic, Dorsweiler, Bergaville, Dieuze itd. Avgusta 1771 je imel Seultour 60 hiš, podatek iz leta 1777 pa govori o 303 prebivalcih, ki so bili v tem času vsi Francozi. Že sredi 19.stoletja pa se začne etnična podoba vasi spreminjati. Neki madžarski dokument ${ }^{7}$ navaja: "Szolturn, franczia falu, Torontál varmégyeben, Komlóshoz 1 mfldnyre, 706 kath., 24 óhitü, 2 zsidó..." Po avstro-ogrski nagodbi leta 1867 srečamo ime v nekaj variantah: Seultourn, Soltur, Szolturn, Solturn, uradno pa Szent-Borbala. Po letu 1918 so jugoslovanske oblasti (Kraljevina SHS) vrnile vasi prejšnje ime, ki ga ima vse do leta 1947, ko skupaj s Sarlevilom in Svetim Hubertom dobi novo, današnje ime - Banatsko Veliko Selo.

Gl. opombo 4.

7 Fényes, Magyarország geographiai szótára... IV, str. 146. 
SVETI HUBERT - pri Kikindi, na državni meji z Romunijo. Saint-Hubert 1771, ko je vas ustanovljena oziroma zgrajena za francoske koloniste. Podatek iz leta 1772 pravi, da je imela vas 80 hiš, leta 1777 pa kar 415 prebivalcev. Sedemdeset let pozneje lahko beremo, da je „Szent-Hubert, franczia falu, Torontál vmegyében, ut. p. Komlóshoz délre 11/4 mfldnyire, 976 kath., 44 óhitü, 14 zsidó lak...". ${ }^{8}$ Krajevno ime so prinesli kolonisti sami: pri Metzu je izvirni SaintHubert. Državna nagodba ni prinesla kake pomembnejše spremembe - ne fonetske ne grafične - , tako kot pri Charlevillu in Seultouru. Po letu 1918 je ime seveda Sveti Hubert, od leta 1947 pa Banatsko Veliko Selo.

ŠARLEVIL - pri Kikindi, na državni meji z Romunijo. Charleville 1771, ko je vas namenoma zgrajena za francoske koloniste. Ti so dali vasi ime kot spomin na rojstni kraj (mesto Charleville pri Metzu). Po avstro-ogrski nagcdbi leta 1867 in hudi madžarizaciji se ime spremeni v Karolyliget, ki ostane vse do prve svetovne vojne. Zanimivo je, da je Kraljevina SHS leta 1918 vasi vrnila francosko ime (na smerokazih zapisano v cirilici in latinici kot Šarlevil). Tako je bilo vse do leta 1947, ko se etnična podoba vasi s prihodom novih kolonistov iz Bosne in Like popolnoma spremeni. Danes vse tri nekdanje vasi - Soltur, Sveti Hubert in Sarlevil - nosijo skupno ime Banatsko Veliko Selo. ${ }^{9}$

TALIJAN MJR - severni Banat, vzhodno od Novega Kneževca. Tallian (Nágy) mjr 1894, Talijanov majur 1925, Talijan majur 1949.

TRANDZ̆AMENT - še v 17. stoletju, toponim pri Novem Sadu. Po ljudski etimologiji ima to ime izvor $\mathrm{v}$ turščini, $\mathrm{v}$ resnici pa izvira iz fr. (re)tranchement. Dovolj je upoštevati dejstvo, da je Petrovaradinski grad sezidan po načrtih francoskega inženirja Vaubana.

Na koncu seznama še to. Obstajali sta še dve etnično čisti francoski vasi: Trübswetter/Nagyösz, danes Tomnatic, in Ostern/Kis-Komlos, danes Comloşu Mic. Obe sta ostali na romunski strani, ko je bila leta 1918 tod potegnjena meja. Dodajmo še, da je bil Temišvar mesto $\mathrm{z}$ največjo koncentracijo italijanskega koloniziranega prebivalstva in da se onstran meje najdejo vasi kot Karbonar ipd. ${ }^{10}$

\section{LITERATURA}

Arsenijević, M.: La présence des Français dans le Banat au XVIIIe siècle, v: Actes du XVIIIe Congrès International de Linguistique et Philologie Romanes, Trèves 1986, Tübigen, 1989.

Borovszky, Samu: Torontál varmegye, Budapest [s. a.].

Fényes, Elek: Magyarország geographiai szótára ... I-IV, Pesten, 1851.

$8 \quad$ Prav tam, str. 99.

9 Zanimivo je tudi, da po vaseh in v Kikindi današnja mladina delu Banatskega Velikega Sela $v$ slengu pravi Šarlah. Ko sem neko študent ko od tod povprašal, zakaj pravijo tako in kaj pomeni to ime, ni vedela odgovora.

10 Dva od štirih delov romunskega mesta Oradea Mare/Nagy-Varad sta se v 19. stoletju imenovala Olaszi-Varad in Velence-Varad, (olaszi 'italijanski'; Velence 'Benetke'). 
General-Karte der Wojwodschaft Serbien und des Temescher Banates ... im Jahre 1853, Geographische Karte.

Handbuch der Wojwodschaft Serbien und des Temeser Banates sammt der Militärgrenze für das Jahr 1854, Temesvar, 1854.

Hess, Nikolaus: Heimatbuch der drei Schwestergemeinden Sveti-Hubert, Charlevil und Soltour im Banat 1770 - 1927, Sv. Hubert, 1927.

Kiss, Lajos: Földrajzi nevek etimólogiai szótára, Budapest, 1988.

Magyarország varmegyei és városai encziklopediaja, Budapest, 1911.

Marković, Milica: Geografsko-istorijski imenik naselja Vojvodine..., Novi Sad, 1966.

Milleker, Felix: Geschichte der Stadt Veliki Bečkerek 1333-1918, Wrschatz, 1933.

Milleker, Felix: Versuch einer Einsiedlung von Spaniern im Banat, Wrschatz, 1937.

Milleker, Srećko: Povesnica slobodne kraljeve varoši Vršca, Pančevo, 1886.

Ovadija, J. M.: Imenik naselja Kraljevine Jugoslavije, Beograd, 1935.

Schünemann, Konrad: Österreichs Bevölkerungspolitik unter Maria Theresia, Berlin, 1935.

Skok, Petar: Toponomastika Vojvodine, v: Vojvodina I, Novi Sad, 1939.

Stanglica, Franz: Die Auswanderung der Lothringer in das Banat und die Batschka im 18. Jahrhundert, Frankfurt a. M., 1934.

Torontaler Kompass, Staatliches Jahrbuch..., Budapest, 1880.

Resumé

QUELQUES TRAITS ROMANS DANS LA TOPONOMASTIQUE DE LA VOÏVODINE

Dans ce travail, l'auteur se propose de donner une contribution à l'étude des noms de lieux de la Voïvodine intéressants pour leur origine romane. En effet, au cours du XVIII siècle, l'Autriche effectuait une colonisation dans ses territoires néonacquis, en y amenant, entre autres, les Français, les Espagnols et les Italiens. La présence de ces trois groupes ethniques a laissé des traces dans certains noms de villages et de lieux-dits de cette province au Nord de la Yougoslavie. 